\title{
Simulation of heat recovery from data centers using heat pumps
}

\author{
Mohammad Sharfuddin Lars Erik Øi \\ Department of Process, Energy and Environmental Technology, University of South-Eastern Norway
}

lars.oi@usn.no

\begin{abstract}
Digitalization has influenced the rapid growth of data centers around the world. The advancement of IT and telecommunication also played a vital role in this expansion of data centers. Data centers facilitate the storage and access of data when required. Electric power is the main energy input and heat is the main energy output from the data center. This work is about the utilization of the excess heat which is the by-product of data center operation. Possible ways to utilize waste heat from data centers have been evaluated. To connect the heat from data centers to a district heating network, a heat pump might be necessary to increase the temperature of the heat. Simulations were performed at varying conditions in Aspen HYSYS to evaluate the waste heat utilization. The economic potential for different conditions and different heat recovery solutions are also evaluated.
\end{abstract}

Keywords: data center, district heating, heat recovery, heat pump, Aspen HYSYS.

\section{Introduction}

Data centers have become an indispensable part of the modern digitalized world. Digitalization demands the storage of constantly and rapidly expanding data around the globe, for which the number of data centers is everincreasing. Apart from digitalization, speedy wireless networks, growing demand for cloud computing have added the crying needs of data centers. The U.S. Environment Protection Agency defines a data center as (Geng, 2014): "Primarily electronic equipment used for data processing (servers), data storage (storage equipment), and communications (network equipment). Collectively, these equipment processes, stores, and transmits digital information".

Data centers are run by electricity and the functioning of different equipment release heat. So, all the electricity input is converted to heat. Studies show that the electricity requirement for data center has increased from about $1.3 \%$ of the world's total electricity consumption in 2010 to $2 \%$ in 2018 and with this pace, it will reach up to $13 \%$ in 2030 (Oltmanns et al., 2020).
However, the energy source which is still dependent on the fossil fuels are gradually decreasing because of the ever-growing consumption. So, the dire need for renewable energy sources is beyond description. The rejected or output heat from data centers could be a useful source of renewable energy. So, the waste heat utilization from data centers has become one of the prime researches for the scientists and data center operator to make data centers energy efficient and economically sound.

Data centers reject a vast amount of heat which is the conversion of electricity. For the proper and reliable functioning of the data center cooling down of different IT equipment is essential. $40 \%$ of the total energy consumption in a DC can be spent in the cooling system (Capozzoli and Primiceri, 2015). Moreover, excess or rejected heat from a DC can be regarded as lost energy. To make data centers more energy-efficient these lost energies should be utilized. The utilization will be economically profitable also. Furthermore, the cold climate of Nordic countries makes it easy for data centers to provide cooling energy. Besides, the high demand for heat in these countries makes it more convenient to utilize the waste heat. Thus, the necessity of waste heat utilization from data centers arises. The work will also focus on the possible utilization of waste heat using a heat pump in the district heating facility.

\section{Literature Review}

\subsection{General literature on energy recovery from data centers}

Ebrahimi et al. (2014) investigated different waste heat recovery technologies from the data center. They suggested that district heating is a common low-quality waste heat recovery technique which is also economically and ecologically sound. Liquid-cooled servers are more compatible with the higher waste recovery temperatures. Liquid-cooled servers can provide waste heat of up to $50-60^{\circ} \mathrm{C}$ (Ebrahimi et al., 2014) that can be applied to district heating over a long area. This waste heat recovery technique is economically profitable as it can earn a revenue stream for data center operators. 
The next option found by Ebrahimi et al. (2014) was the heating of water in a thermal Rankine cycle. The waste heat cannot fully replace the boiler but can be used to preheat boiler feedwater. So, the consumption of fossil fuel and pollution can be decreased to some extent. Moreover, they suggested on-chip two-phase cooled data centers to utilize most of this technology. The sale of heat to the power plant and carbon offsets can produce substantial income.

Absorption cooling is another choice for utilizing data center waste heat as studied by Ebrahimi et al. (2014) Absorption refrigeration systems can function with generator temperatures of $70-90^{\circ} \mathrm{C}$ which could be supplied by the waste heat from a water-cooled and twophase cooled data center. An air-cooled data center is not viable for the technology. This technique can minimize the load on data center CRAC (computer room air conditioning) systems by producing chilled water for cooling and thus become economically profitable.

Ebrahimi et al. (2014) also proposed that organic Rankine cycle (ORC), multiple-effect distillation (MED), direct power generation like piezoelectric and thermoelectric, biomass co-location are the possible techniques that can be useful to utilize the low-grade waste heat from data centers.

Oltmanns et al. (2020) proposed a new cooling concept which TU Darmstadt will employ in the next generation of the current air-cooled servers with watercooled rear doors. The new data center will use direct hot-water cooling for the high-performance computer, providing heat at $45^{\circ} \mathrm{C}$. The waste heat will be utilized for heating the university's campus Lichtwiese. They suggested two ideas, either heat integration in the return line of the district heating network or utilizing it locally in buildings situated near the data center. The project showed that $20-50 \%$ of the waste heat rejected by the high-performance computer can be utilized in the heating sector. A significant reduction of $\mathrm{CO}_{2}$ emission can also be achieved through the project.

Oró et al. (2018) studied a liquid-cooled on-chip server numerically for a case study of utilizing the waste heat for an indoor swimming pool heating. For the most suitable solution, the data center operator decreases its operational costs and produces surplus income by selling the excess heat, obtaining a net present value after 15 years of $330,000 €$. Besides the operational cost of the indoor swimming pool was reduced by $18 \%$. The case study was implemented for the assessment of Barcelona's indoor swimming pools.

\subsection{Possible temperatures in cooling principle in data centers}

For the efficient and proper utilization of excess heat from the data centers determining the temperature of the cooling system is not only very essential but also very sensitive. Depending on the temperature range the quality of the heat will be evaluated. The investigation is not a very easy task rather it has been a matter of argument.

ASHRAE Technical Committee 9.9 has done a significant job to determine the favorable environment and temperature range for data centers. This is a common thermal guideline. ASHRAE (2011) recommended that the data center's equipment should maintain the temperature range between $18^{\circ} \mathrm{C}$ and $27^{\circ} \mathrm{C}$ to fit the manufacturer's provided criteria. The Technical Committee also classified the data center based on their temperature range. For the $\mathrm{A} 1$ data center, the temperature range was $15^{\circ} \mathrm{C}$ to $32^{\circ} \mathrm{C}$, for the $\mathrm{A} 2$ category the range was set to $10^{\circ} \mathrm{C}$ to $35^{\circ} \mathrm{C}$. For class $\mathrm{A} 3$ and $\mathrm{A} 4$ data center they increased the temperature range by $5^{\circ} \mathrm{C}$ to $40^{\circ} \mathrm{C}$ and $5^{\circ} \mathrm{C}$ to $45^{\circ} \mathrm{C}$, respectively.

Oltmanns et al. (2020) studied that the high cooling inlet temperatures of up to $60^{\circ} \mathrm{C}$ for water-cooled data center allow the possibilities for better waste heat utilization.

According to Patel (2003) for an efficient aircooling system, the cold air should be supplied at $25^{\circ} \mathrm{C}$ and exhaust air should exit the room and come back to CRAC at $40^{\circ} \mathrm{C}$.

Ebrahimi et al. (2014) suggested that the optimum temperature range to utilize the waste heat in the aircooled data center at rack exit is $30-40^{\circ} \mathrm{C}$ while for the chiller water return the suitable temperature range is $16-$ $18^{\circ} \mathrm{C}$.

Brunschwiler et al. (2009) found that the inlet water temperature can be $60^{\circ} \mathrm{C}$ to keep the junction temperature under $85^{\circ} \mathrm{C}$. For this criterion, the maximum inlet temperature could be as high as $75^{\circ} \mathrm{C}$.

Sharma et al. (2012) depicted that to recover maximum waste heat the suitable inlet temperature can be in the range $40-40.7^{\circ} \mathrm{C}$. They suggested microprocessor junction temperature can be a maximum of $90^{\circ} \mathrm{C}$.

\section{Process Description}

Heat pump technology gives an effective and longlasting solution for both heating and cooling applications. A conventional heat pump is a system working on the compression refrigeration cycle powered by either mechanical energy or electricity (Øi and Tirados, 2015). In data center cooling for both aircooled and liquid-cooled process heat pump is an essential part that regulates the cooling medium's temperature. Typical refrigerants used in heat pumps are ammonia and chlorinated or fluorinated hydrocarbons electricity (Øi and Tirados, 2015).

In the refrigeration cycle, the refrigerant circulates due to temperature and pressure difference between the components. The four main components of 
a refrigeration cycle are the compressor, condenser, expansion valve, and evaporator. Figure 1 depicts the mechanical compression refrigeration cycle of a traditional heat pump. The red lines represent high pressure and temperature and the blue line indicates low pressure and temperature of the refrigerant. The cooling effect is produced by the cold liquid refrigerant in the evaporator. A mixture of vapor and liquid phased refrigerant goes into the evaporator where the vaporization of liquid provides the cooling effect before leaving the evaporator. The vapor refrigerant is sucked by the compressor where it gains high pressure and becomes superheated. The output from the compressor then enters the condenser. In the condenser, the vapor refrigerant is cooled and condensed to a saturated liquid. Heat is released from the refrigerant to the ambient (Smith, 2005).

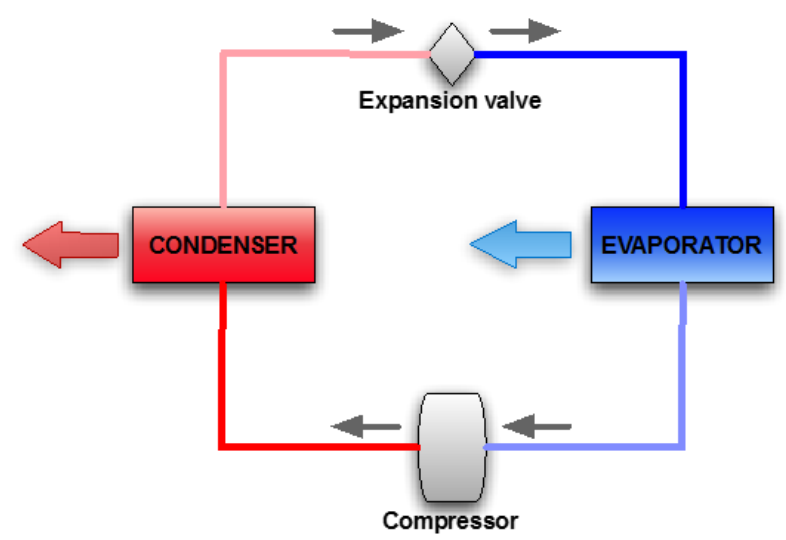

Figure 1. Schematic diagram of a heat pump's mechanical compression cycle (Øi and Tirados, 2015).

The liquid refrigerant then enters the expansion device typically an expansion valve where it is expanded to lower pressure. The liquid refrigerant is partially vaporized due to the expansion process giving a cooling effect in the refrigeration cycle (Smith, 2005).

The efficiency of a heat pump is measured by the coefficient of performance (COP). It is the ratio of the heat delivered or supplied at high temperature to the required power. Equation 1 represents the COP of the heat pump (Øi and Tirados, 2015).

$$
\begin{gathered}
C O P=\frac{Q_{C}}{W} \\
W=Q_{C}-Q_{E}
\end{gathered}
$$

In Equation $2 \mathrm{Q}_{\mathrm{C}}$ is the amount of heat output from the condenser, $\mathrm{Q}_{\mathrm{E}}$ is the amount of heat input from the evaporator, and $\mathrm{W}$ is the power required in the compressor. When there is no heat loss the work added in the refrigeration cycle is equal to the difference between heat output and heat input ( $\varnothing_{\mathrm{i}}$ and Tirados, 2015).
Typical COP values calculated in the work of $\varnothing_{i}$ and Tirados (2015) are between 3 and 10, dependent on the difference between the delivery and output temperature.

\section{Process Simulation, Results and Discussion}

\subsection{Simulation setup in Aspen HYSYS}

For calculation and simulation first, the simulation was set up in the Aspen HYSYS. Version 10 of Aspen HYSYS was used for simulation. In the component lists two pure components described. The components are pure water and pure Refrig-22(R-22). R-22 was selected as the refrigerant medium and water which will be supplied for the cooling process in the data center was selected. After that, in the fluid packages, PengRobinson (PR) package was selected which is the most common and efficient package for HYSYS simulation. The default parameters for the package was used by Aspen HYSYS. Then the units of the heat pump which are evaporator, condenser, compressor, and expansion valve, were defined for the simulation with relevant streams.

\subsection{The energy required calculation from Aspen HYSYS}

One of the important tasks of the work is to perform the calculation in Aspen HYSYS. Two alternatives were selected for the simulation in the Aspen HYSYS. The setup condition for the alternatives are shown in Table 1 and Table 2.

Table 1. Aspen HYSYS input condition for alternative 1

\begin{tabular}{|c|c|c|}
\hline Stream name & Water 1 & Water 6 \\
\hline Temperature $\left.\mathbf{(}^{\mathbf{0}} \mathbf{C}\right)$ & 65 & 70 \\
\hline Pressure $(\mathbf{k P a})$ & 101 & 101 \\
\hline Fluid package & \multicolumn{2}{|c|}{ Peng-Robinson } \\
\hline
\end{tabular}

Table 2. Aspen HYSYS input condition for alternative 2

\begin{tabular}{|c|c|c|}
\hline Stream name & Water 1 & Water 6 \\
\hline Temperature $\left.\mathbf{(}^{\mathbf{}} \mathbf{C}\right)$ & 65 & 80 \\
\hline Pressure $(\mathbf{k P a})$ & 101 & 101 \\
\hline Fluid package & \multicolumn{2}{|c|}{ Peng-Robinson } \\
\hline
\end{tabular}

An Aspen HYSYS flow-sheet model of the process for the simulation is presented in Figure 2. 


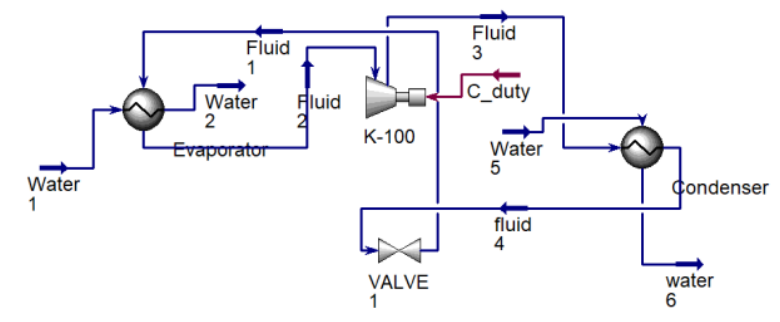

Figure 2. Model representation of the DC heat recovery process via heat pump in Aspen HYSYS

Water 1 is the cooling water from the data center and water 6 is water supplied to the district heating network. The result of the simulation was obtained in a very short time as the simulation in Aspen HYSYS is very quick and efficient. The simulation results for the two alternatives are presented in Table 3 and Table 4.

Table 3. Results of material and energy balance achieved from Aspen HYSYS for alternative 1

\begin{tabular}{|c|c|c|c|c|c|c|c|c|}
\hline & $\begin{array}{l}\text { Wa } \\
\text { t } 1\end{array}$ & $\begin{array}{c}\text { Fluid } \\
1\end{array}$ & Wat 2 & $\begin{array}{c}\text { Fluid } \\
\mathbf{2}\end{array}$ & $\begin{array}{c}\text { Fluid } \\
\mathbf{3}\end{array}$ & Wat 5 & $\begin{array}{c}\text { Wat } \\
6\end{array}$ & $\begin{array}{c}\text { Fluid } \\
4\end{array}$ \\
\hline $\mathrm{T}\left({ }^{\circ} \mathrm{C}\right)$ & 65 & 51.24 & 55 & 51.24 & 88.84 & 40 & 70 & 74.25 \\
\hline $\begin{array}{c}\mathbf{P} \\
(\mathbf{k P a})\end{array}$ & 101 & 2000 & 101 & 2000 & 3280 & 101 & 101 & 3280 \\
\hline $\begin{array}{c}\text { Flow } \\
\text { (kgmo } \\
\text { le/h) }\end{array}$ & 55. & 4.369 & 55.51 & 4.369 & 4.369 & 20.94 & 20.94 & 4.369 \\
\hline $\begin{array}{c}\text { Flow } \\
\text { (kg/h) }\end{array}$ & 1000 & 377.8 & 1000 & 377.8 & 377.8 & 377.1 & 377.1 & 377.8 \\
\hline $\begin{array}{c}\text { Liq } \\
\text { flow } \\
\left(\mathbf{m}^{3} / \mathbf{h}\right)\end{array}$ & 1.0 & 0.308 & 1.002 & 0.308 & 0.308 & 0.377 & 0.377 & 0.308 \\
\hline $\begin{array}{c}\text { Heat } \\
\text { flow } \\
(\mathbf{k J} / \mathbf{h})\end{array}$ & $\begin{array}{c}1.5 \mathrm{e} \\
+7\end{array}$ & $\begin{array}{l}2.131 \\
\mathrm{e}+06\end{array}$ & $\begin{array}{l}1.576 \\
\mathrm{e}+07\end{array}$ & $\begin{array}{l}2.088 \\
\mathrm{e}+06\end{array}$ & $\begin{array}{l}2.082 \\
\mathrm{e}+06\end{array}$ & $\begin{array}{l}5.968 \\
\mathrm{e}+06\end{array}$ & $\begin{array}{l}5.919 \\
\mathrm{e}+06\end{array}$ & $\begin{array}{r}2.131 \\
\mathrm{e}+06\end{array}$ \\
\hline
\end{tabular}

Table 4. Results of material and energy balance achieved from Aspen HYSYS for alternative 2

\begin{tabular}{|c|c|c|c|c|c|c|c|c|}
\hline & $\begin{array}{l}\text { Wa } \\
\text { ter } \\
1\end{array}$ & $\begin{array}{l}\text { Fluid } \\
1\end{array}$ & $\begin{array}{l}\text { Wate } \\
\text { r } 2\end{array}$ & $\begin{array}{l}\text { Fluid } \\
2\end{array}$ & $\begin{array}{l}\text { Fluid } \\
\mathbf{3}\end{array}$ & $\begin{array}{l}\text { Wate } \\
\text { r5 }\end{array}$ & $\begin{array}{l}\text { Wate } \\
\text { r } 6\end{array}$ & $\begin{array}{l}\text { Fluid } \\
4\end{array}$ \\
\hline $\mathbf{T}\left({ }^{\circ} \mathbf{C}\right)$ & 65 & 51.24 & 55 & 51.24 & 104.7 & 40 & 80 & 84.33 \\
\hline $\begin{array}{c}\mathbf{P} \\
(\mathbf{k P a})\end{array}$ & 101 & 2000 & 101 & 2000 & 4000 & 101 & 101 & 4000 \\
\hline $\begin{array}{c}\text { Flow } \\
\text { (kgmo } \\
\text { le/h) }\end{array}$ & 55. & 5.419 & 55.51 & 5.419 & 5.419 & 17.02 & 17.02 & 5.419 \\
\hline $\begin{array}{c}\text { Mass } \\
\text { flow } \\
(\mathbf{k g} / \mathbf{h})\end{array}$ & 1000 & 468.6 & 1000 & 468.6 & 468.6 & 306.6 & 306.6 & 468.6 \\
\hline $\begin{array}{c}\text { Liq } \\
\text { flow } \\
\left(\mathbf{m}^{3} / \mathbf{h}\right)\end{array}$ & 1.0 & 0.382 & 1.002 & 0.382 & 0.382 & 0.307 & 0.307 & 0.382 \\
\hline $\begin{array}{c}\text { Heat } \\
\text { flow } \\
(\mathbf{k J} / \mathbf{h})\end{array}$ & $\begin{array}{c}1.5 \mathrm{e} \\
+7\end{array}$ & $\begin{array}{l}2.633 \\
\mathrm{e}+06\end{array}$ & $\begin{array}{l}1.576 \\
\mathrm{e}+07\end{array}$ & $\begin{array}{l}2.590 \\
\mathrm{e}+06\end{array}$ & $\begin{array}{l}2.580 \\
\mathrm{e}+06\end{array}$ & $\begin{array}{l}4.851 \\
\mathrm{e}+06\end{array}$ & $\begin{array}{l}4.798 \\
\mathrm{e}+06\end{array}$ & $\begin{array}{r}2.633 \\
\mathrm{e}+06\end{array}$ \\
\hline
\end{tabular}

\subsection{Calculation of COP for heat pump}

For alternative 1

The evaporation temperature from the simulation is found $51.24^{\circ} \mathrm{C}$.

Condensation temperature from the simulation is found $74.25^{\circ} \mathrm{C}$.
From the simulation the amount of heat output from the condenser, $\mathrm{Q}_{\mathrm{C}}=48950 \mathrm{~kJ} / \mathrm{h}$.

From the simulation power required in the compressor, $\mathrm{W}=5651 \mathrm{~kJ} / \mathrm{h}$.

$C O P=\frac{Q_{C}}{W}=\frac{48950}{5651}=8.66$

For alternative 2

The evaporation temperature from the simulation is found $51.24^{\circ} \mathrm{C}$.

Condensation temperature from the simulation is found $84.33^{\circ} \mathrm{C}$.

From the simulation the amount of heat output from the condenser, $\mathrm{Q}_{\mathrm{C}}=53130 \mathrm{~kJ} / \mathrm{h}$.

From the simulation power required in the compressor, $\mathrm{W}=9829 \mathrm{~kJ} / \mathrm{h}$.

$C O P=\frac{Q_{C}}{W}=\frac{53130}{9829}=5.4$

So, when the cooling water from the data center is $65^{\circ} \mathrm{C}$ and the supply water to district heating is $70^{\circ} \mathrm{C}$ the COP is found 8.66. On the other hand, when the cooling water from the data center is $65^{\circ} \mathrm{C}$ and the supply water to district heating is $80^{\circ} \mathrm{C}$ the $\mathrm{COP}$ is found 5.4. The two COP values can be compared to an average performance COP value of 6.8 from Oltmanns et al. (2020). In that case the cooling water input was $45^{\circ} \mathrm{C}$ and the return temperature for the heat delivery system varied between 50 and $70{ }^{\circ} \mathrm{C}$.

\subsection{Economic calculation}

For the energy cost calculation, simple assumptions are made. The price of electricity is estimated to be 0.1 $\mathrm{EUR} / \mathrm{kWh}$, and the district heat price was specified to $0.05 \mathrm{EUR} / \mathrm{kWh}$.

So, the formula for the estimated economic potential is presented in equation 3 .

$$
\begin{aligned}
& \text { Economic potential } \\
&=\text { Price } \cdot \text { Recovered heat } \\
&-(\text { Elc.price } \\
&\left.\cdot \frac{\text { Recovered heat }}{\text { COP }}\right)
\end{aligned}
$$

Oltmanns et al. (2020) have found that in 2018 the Telia data center in Helsinki, Finland supplied 200GWh/a in the nearby city of Espoo. So, taking this recovered heat value as a reference, the economy for a large data center facility can be calculated.

For alternative 1

Economic potential $=0.05 \frac{E U R}{k W h} \cdot 200 G W h-\left(0.1 \frac{E U R}{k W h}\right.$. $\left.\frac{200 G W h}{8.66}\right)=7.7$ MEUR 
For alternative 2

Economic potential $=0.05 \frac{E U R}{k W h} \cdot 200 G W h-\left(0.1 \frac{E U R}{k W h}\right.$. $\left.\frac{200 G W h}{5.4}\right)=6.3$ MEUR

For the case of omitting heat pump, all the $200 \mathrm{GW}$ energy can be utilized to district heating network, which is worth of value $10 \mathrm{MEUR}$, as per $\mathrm{kW}$ district heat price is 0.05 EUR.

The investment cost is mostly dependent on the installation cost of the heat pump facility. Other costs can be negligible for the heat recovery solution. The heat pump cost is very critical to determine. From the study of Nishihata et al. (2013) the installed cost for a $2 \mathrm{~kW}$ pump is found to be 552.4 EUR. Thus, for a $24 \mathrm{MW}$ capacity data center, the cost of the heat pump will be equal to 6.6 MEUR. Hence for a large amount of heat recovery from $\mathrm{DC}$, it can be estimated that the investment of heat pump cost is high enough.

If the project is run for 10 years, the economic value for all three alternatives to be calculated. The factor for constant income is given by equation

$$
\text { Factor }=\frac{1-(1+i)^{-n}}{i}
$$

For $\mathrm{n}=10$ years and $\mathrm{i}=7 \%$, the factor is 7.02 .

The economic result is to be calculated by equation 5

Economic result

$$
\begin{aligned}
& =\text { Economic potential } \\
& \text { - Factor } \\
& \text { - Investment cost }
\end{aligned}
$$

For alternative 1

The economic result $=7.7 \cdot 7.02-6.6=47.45$ MEUR For alternative 2

The economic result $=6.3 \cdot 7.02-6.6=37.63$ MEUR For the alternative without a heat pump, there will be no investment cost. So, the economic result will be 70.2 MEUR.

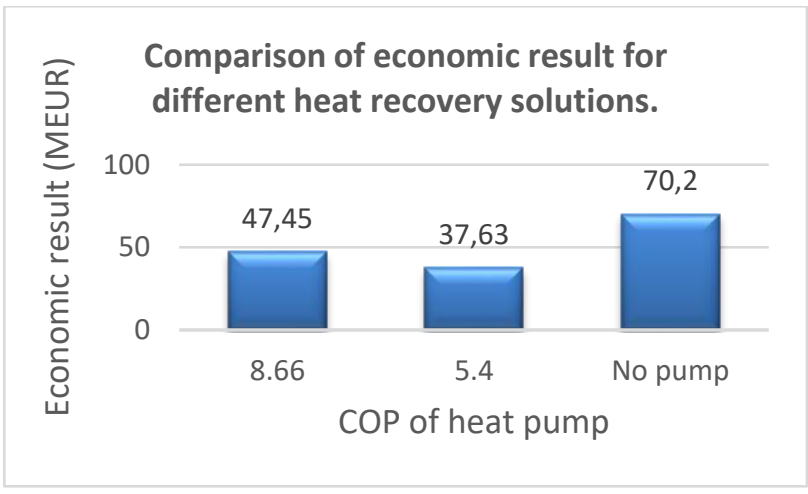

Figure 3. COP of pump versus the economic value of heat recovery solutions
The comparison of the economic results for different heat recovery scenarios is represented in Figure 3.

\subsection{Evaluation of uncertainties}

The three alternative solutions for heat recovery from a data center depend on certain things. The most vital thing is the temperature dependency. The required cooling temperature specified by data centers and the required temperature for the district heating network should be specified by the respective companies. In future work, it would be interesting to continue this work based on data from existing data centers. These two temperatures play a vital role in heat recovery solutions. If the temperatures change the value of the economic result will also vary. Besides the prices of electricity and district heating may vary country wise which will also affect the result. For the required calculation, they are assumed. Moreover, pipeline cost is very difficult to estimate as it depends on the climate, length of connection, and environmental condition. However, it can be assumed that the heat pump cost is relatively larger than the pipeline cost.

\section{Conclusion}

Simulations and economical optimization at different conditions in Aspen HYSYS were carried out. Especially three alternatives were evaluated. The first is an alternative without a heat pump in which the cooling water leaves the data center at $80^{\circ} \mathrm{C}$ and enters the district heat network at $70{ }^{\circ} \mathrm{C}$. The second is an alternative with a slight temperature increase in the heat pump. The cooling water temperature from the data center is $65^{\circ} \mathrm{C}$ and the temperature to the district heat system is $70^{\circ} \mathrm{C}$. The third is an alternative with a higher temperature increase in the heat pump. The cooling water temperature from the data center is $65^{\circ} \mathrm{C}$ and the temperature to the district heat system is $80{ }^{\circ} \mathrm{C}$. The COP (Coefficient of Performance) in a heat pump for these alternatives were calculated using the refrigerant R-22 in the simulation program Aspen HYSYS. The estimated economic potential for each alternative was calculated by estimated values on electricity cost and district heat price. In one alternative, the electricity cost was specified to $0.1 \mathrm{EUR} / \mathrm{kWh}$, and the district heat price was specified to $0.05 \mathrm{EUR} / \mathrm{kWh}$. For the alternatives using heat pumps, the capital cost was estimated assuming that the heat pump investment was dominating.

The COPs for the two heat pump alternatives were calculated to be 8.66 and 5.4, respectively. The economy for a large data center facility with recovered waste heat of $200 \mathrm{GWh} /$ year was calculated for 10 years. 
For the specified conditions, the net present value was calculated to be large and positive for all the alternatives. As expected, the most economical alternative was without a heat pump, and the most economical heat pump was the one with the highest COP. Pipeline cost is very much dependent on the length and the local conditions for which it was not possible to make a reasonable estimation.

The calculations show that there is a large potential in using waste heat from data centers for district heating.

\section{References}

A. Almoli, A. Thompson, N. Kapur, J. Summers, H. Thompson, and G. Hannah. Computational fluid dynamic investigation of liquid rack cooling in data centres, Applied energy, $89(1): 150-155$, 2012. doi:10.1016/j.apenergy.2011.02.003

ASHRAE. Thermal guidelines for data processing environments-expanded data center classes and usage guidance. Whitepaper prepared by ASHRAE technical committee (TC), 9, 2011.

L. Bellia, A. Capozzoli, P. Mazzei, and F. Minichiello. A comparison of HVAC systems for artwork conservation. International Journal of Refrigeration, 30(8): 1439-1451, 2007. doi:10.1016/j.jirefrig.2007.03.005

T. Brunschwiler, B. Smith, E. Ruetsche, and B. Michel. Toward zero-emission data centers through direct reuse of thermal energy. IBM Journal of Research and Development, 53(3):1-11, 2009. doi: 10.1147/JRD.2009.5429024

A. Capozzoli, M. Chinnici, M. Perino, and G. Serale. Review on performance metrics for energy efficiency in data center: The role of thermal management. In International Workshop on Energy Efficient Data Centers, Springer, pages 135-151, 2014. doi: 10.1007/978-3-319-15786-3_9

A. Capozzoli and G. Primiceri. Cooling systems in data centers: state of art and emerging technologies. Energy Procedia, 83:484-493, $2015 . \quad$ doi: 10.1016/j.egypro.2015.12.168

A. Capozzoli, G. Serale, L. Liuzzo, and M. Chinnici. Thermal metrics for data centers: A critical review. Energy Procedia, 62:391-400, 2014. doi:10.1016/j.egypro.2014.12.401

Y. Q. Chi et al. Case study of a data centre using enclosed, immersed, direct liquid-cooled servers. In Semiconductor Thermal Measurement and Management Symposium (SEMI-THERM), 2014: IEEE, pages 164-173, 2014. doi:10.1109/SEMI-THERM.2014.6892234

K. Dunlap and N. Rasmussen. Choosing between room, row, and rack-based cooling for data centers. APC White Paper, 130, 2012.

K. Ebrahimi, G. F. Jones, and A. S. Fleischer. A review of data center cooling technology, operating conditions and the corresponding low-grade waste heat recovery opportunities. Renewable and Sustainable Energy Reviews, 31:622-638, 2014. doi: 10.1016/j.rser.2013.12.007

H. Geng. Data center handbook. John Wiley \& Sons, 2014.
M. Iyengar et al. Server liquid cooling with chiller-less data center design to enable significant energy savings. In 28th annual IEEE semiconductor thermal measurement and management symposium (SEMI-THERM), IEEE, pages 212-223, 2012. doi:10.1109/STHERM.2012.6188851

M. Iyengar et al. Extreme energy efficiency using water cooled servers inside a chiller-less data center. In 13th InterSociety Conference on Thermal and Thermomechanical Phenomena in Electronic Systems, IEEE, pages 137-149, 2012. doi: 10.1109/ITHERM.2012.6231424

J. Niemann, K. Brown, and V. Avelar. Impact of hot and cold aisle containment on data center temperature and efficiency. Schneider Electric Data Center Science Center, White Paper, 135, pages 1-14, 2011.

H. Nishihata, R. Kempener, G. Simbolotti, and G. Tosato, Heat Pumps-Technology Brief. International Energy Agency (IEA)_Energy Technology Systems Analysis Programme (ETSAP)/International Renewable Energy Agency (IRENA): Paris, France, page 24, 2013.

M. Ohadi, S. Dessiatoun, K. Choo, M. Pecht, and J. V. Lawler. A comparison analysis of air, liquid, and two-phase cooling of data centers. In 28th Annual IEEE Semiconductor Thermal Measurement and Management Symposium (SEMI-THERM), IEEE, pages 58-63, 2012. doi: 10.1109/STHERM.2012.6188826

J. Oltmanns, D. Sauerwein, F. Dammel, P. Stephan, and C. Kuhn. Potential for waste heat utilization of hot-watercooled data centers: A case study. Energy Science \& Engineering, 2020. doi:10.1002/ese3.633

E. Oró, R. Allepuz, I. Martorell, and J. Salom. Design and economic analysis of liquid cooled data centres for waste heat recovery: A case study for an indoor swimming pool. Sustainable cities and society, 36:185-203, 2018. doi:10.1016/j.scs.2017.10.012

C. D. Patel. A vision of energy aware computing from chips to data centers. In The international symposium on micromechanical engineering, 2003. doi:ISMME2003-K15

R. R. Schmidt, E. E. Cruz, and M. Iyengar. Challenges of data center thermal management. IBM Journal of Research and Development, 49(4.5):709-723, $2005 . \quad$ doi: 10.1147/rd.494.0709

C. S. Sharma, S. Zimmermann, M. K. Tiwari, B. Michel, and D. Poulikakos. Optimal thermal operation of liquid-cooled electronic chips. International journal of heat and mass transfer, 55(7-8):1957-1969, 2012. doi: 10.1016/j.ijheatmasstransfer.2011.11.052

Simple, Science, and Technology. (2011, 15.05.2020). Refrigeration Cycle [Online]. Available: http://simpleengineering.blogspot.com/2011/01/refriger\%20nvbfc\%20d $\mathrm{xz} \% \mathrm{C} 3 \%$ A5ation-cycle.html.

R. Smith, Chemical process: design and integration. John Wiley \& Sons, 2005.

S. Zimmermann, I. Meijer, M. K. Tiwari, S. Paredes, B. Michel, and D. Poulikakos. Aquasar: A hot water cooled data center with direct energy reuse. Energy, 43(1):237245, 2012. doi: 10.1016/j.energy.2012.04.037

L. E. Øi and I. Y. Tirados. Heat Pump Efficiencies simulated in Aspen HYSYS and Aspen Plus. 2015. doi: 10.3384/ecp15119141 